\title{
Effect of allergen challenge on airway responsiveness to histamine and sodium metabisulphite in mild asthma
}

\author{
David J Evans, Lisa J Coulby, Brian J O’Connor
}

\begin{abstract}
Background - Airway responsiveness to histamine and methacholine, direct smooth muscle spasmogens, is increased following inhalation of allergen. Although the aetiology of this phenomenon is unclear, increased cellular or neural activity may be involved since allergen also induces increases in airway responsiveness to the mast cell stimulus adenosine $5^{\prime}$ monophosphate (AMP) and the neural stimulus bradykinin.
\end{abstract}

Methods - To explore this further, the airway responsiveness to sodium metabisulphite (MBS), an indirect neural stimulus with similar characteristics to bradykinin, was compared in 18 mild steroidnaive asthmatic subjects with the airway responsiveness to histamine before and after allergen challenge with extracts of house dust mite, grass pollen, or cat. All subjects inhaled doubling increments of histamine and MBS until the concentration provoking a $20 \%$ fall in forced expiratory volume in one second $\left(\mathbf{P C}_{20}\right)$ was reached before and three hours after allergen challenge. Twelve of the subjects had additional challenges at 24 hours after the allergen.

Results - Following allergen challenge all subjects showed an early response and 14 also had a late asthmatic response. For histamine there was a significant increase in airway responsiveness at both three and 24 hours compared with values before the allergen $(0.89(0.25)$ and $1.53(0.52)$ doubling dose changes, respectively). In contrast, airway responsiveness to $\mathrm{MBS}$ was unaltered by allergen challenge $(0.29(0.27)$ and $-0.33(0.28)$ doubling dose changes compared with pre-allergen values at three and 24 hours, respectively).

Conclusion - These data suggest that activation of airway sensory nerves is unlikely to contribute to the increase in airway responsiveness following inhalation of allergen. The previously observed allergen induced increase in airway responsiveness to bradykinin and AMP may involve non-neural pathways.

(Thorax 1996;51:1185-1191)

Keywords: allergen, airway responsiveness, histamine, metabisulphite.

Increased airway responsiveness is a characteristic feature of asthma. ${ }^{1}$ The degree of bronchial hyperresponsiveness correlates with disease severity and the need for treatment. ${ }^{2}$ Exposure to allergen provokes increased airway responsiveness to several bronchoconstrictor stimuli. ${ }^{34}$ Airway responsiveness to histamine or methacholine, both of which act directly on airway smooth muscle, is increased following allergen challenge and may persist for more than 72 hours. $^{56}$ Changes in airway responsiveness to indirect acting bronchoconstrictor stimuli are less predictable. Airway responsiveness to bradykinin, a neural stimulus, is increased and sustained following allergen challenge, ${ }^{7-9}$ whereas bronchial reactivity to adenosine 5'-monophosphate (AMP), a mast cell stimulus, is increased at three but not at 24 hours after allergen challenge. ${ }^{6}$

The pathogenesis of increased airway responsiveness is unclear, in particular the relationship between airway responsiveness and airway inflammation induced by allergen exposure ${ }^{10}$ The development of the late asthmatic response (LAR) following allergen challenge is dependent upon a complex series of changes in humoral and cellular immune mechanisms resulting in mucosal damage and oedema with infiltration of eosinophils and lymphocytes. ${ }^{34}$ These cells release mediators of inflammation such as cytokines and leukotrienes which not only perpetuate the inflammatory process by recruiting further inflammatory cells but also have direct effects on resident airway cells, mast cells, smooth muscle, and airway nerves that may underlie the changes in airway responsiveness. Thus, allergen induced airway inflammation may result in increased airway responsiveness to both direct and indirect stimuli.

Indirect bronchoconstriction following bradykinin and AMP appears to be specific for asthma and may be a more relevant measurement of airway responsiveness in asthmatic patients than non-specific challenge with histamine or methacholine. ${ }^{11}$ The greater increases in airway responsiveness to bradykinin than methacholine following allergen challenge suggest that upregulation of neural reflexes may occur as a consequence of allergen induced inflammation. ${ }^{8}$ To examine this further we have compared the effect of allergen challenge on airway responsiveness to another indirect spasmogen, metabisulphite (MBS), with airway responsiveness to histamine, a direct spasmogen. MBS provokes cough and bronchoconstriction, suggesting an effect via airway sensory nerves, and exhibits similar characteristics to bradykinin. ${ }^{12}$ This study was de- 
Table 1 Patient details

\begin{tabular}{|c|c|c|c|c|c|c|}
\hline & $\begin{array}{l}\text { Patient } \\
\text { no. }\end{array}$ & $\begin{array}{l}\text { Age } \\
\text { (years) }\end{array}$ & $\begin{array}{l}F E V_{1} \\
\text { (\% predicted) }\end{array}$ & Allergen & $\begin{array}{l}\text { Max \% change } \\
F E V_{I}(E A R)\end{array}$ & $\begin{array}{l}\text { Max \% change } \\
F E V_{I}(L A R)\end{array}$ \\
\hline Phase 1 (all LAR) & $\begin{array}{c}1 \\
2 \\
3 \\
4 \\
5 \\
6 \\
\text { Mean }\end{array}$ & $\begin{array}{l}23 \\
29 \\
32 \\
28 \\
23 \\
30\end{array}$ & $\begin{array}{r}94 \\
90 \\
97 \\
102 \\
94 \\
105\end{array}$ & $\begin{array}{l}\text { Cat } \\
\text { House dust mite } \\
\text { House dust mite } \\
\text { Cat } \\
\text { House dust mite } \\
\text { Grass pollen }\end{array}$ & $\begin{array}{l}19 \\
43 \\
36 \\
29 \\
33 \\
41 \\
33.5(3.6)\end{array}$ & $\begin{array}{l}- \\
- \\
- \\
-\end{array}$ \\
\hline Phase 2 (LAR) & $\begin{array}{l}7 \\
8 \\
9 \\
10 \\
11 \\
12 \\
13 \\
14 \\
\text { Mean }\end{array}$ & $\begin{array}{l}30 \\
29 \\
24 \\
29 \\
29 \\
24 \\
19 \\
21\end{array}$ & $\begin{array}{r}101 \\
103 \\
93 \\
114 \\
91 \\
103 \\
87 \\
91 \\
97.5(2.0)\end{array}$ & $\begin{array}{l}\text { Grass pollen } \\
\text { Grass pollen } \\
\text { House dust mite } \\
\text { Grass pollen } \\
\text { Cat } \\
\text { Grass pollen } \\
\text { House dust mite } \\
\text { Cat }\end{array}$ & $\begin{array}{l}62 \\
49 \\
17 \\
29 \\
30 \\
28 \\
24 \\
22 \\
32.6(5.4)\end{array}$ & $\begin{array}{l}30 \\
31 \\
19 \\
17 \\
19 \\
37 \\
29 \\
20 \\
25.3(2.6)\end{array}$ \\
\hline Phase 2 (no LAR) & $\begin{array}{l}15 \\
16 \\
17 \\
18 \\
\text { Mean }\end{array}$ & $\begin{array}{l}25 \\
24 \\
25 \\
32\end{array}$ & $\begin{array}{l}100 \\
99 \\
89 \\
94 \\
95.5(2.5)\end{array}$ & $\begin{array}{l}\text { House dust mite } \\
\text { House dust mite } \\
\text { House dust mite } \\
\text { Cat }\end{array}$ & $\begin{array}{l}24 \\
36 \\
38 \\
31 \\
32.3(3.1)\end{array}$ & $\begin{array}{r}13 \\
6 \\
7 \\
10 \\
9.0(1.6)\end{array}$ \\
\hline
\end{tabular}

$\mathrm{FEV}_{1}=$ forced expiratory volume in one second; EAR = early asthmatic response; LAR = late asthmatic response.

signed to explore the involvement of airway neural mechanisms following allergen challenge using MBS as a measure of airway responsiveness.

\section{Methods}

SUBJECTS

Eighteen non-smoking subjects (12 men) with mild asthma (as defined by documented peak flow variability and episodic wheeze relieved by $\beta_{2}$ agonists) gave written informed consent to participate in the study which was approved by the Royal Brompton and National Heart Hospitals ethics committee. All subjects were admitted to the Clinical Studies Unit of the Royal Brompton Hospital. All were atopic as defined by skin prick testing to common aeroallergens (Dermatophagoides pteronyssinus, mixed grass pollen, cat hair). None had suffered an exacerbation of wheeze nor a respiratory infection within the previous six weeks. Each subject had clinical features of asthma which were controlled with $\beta_{2}$ adrenoceptor agonists alone, and had a baseline forced expiratory volume in one second $\left(\mathrm{FEV}_{1}\right)$ in excess of $80 \%$ of their predicted value (individual characteristics summarised in table 1). Inhaled sympathomimetics and caffeinated beverages were withheld for at least eight hours before each study.

\section{Phase 1}

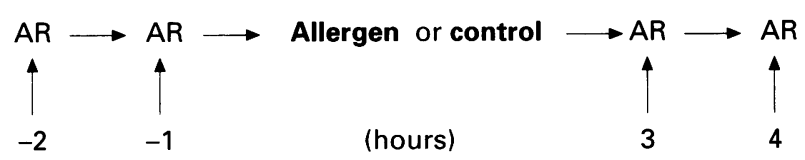

Phase 2

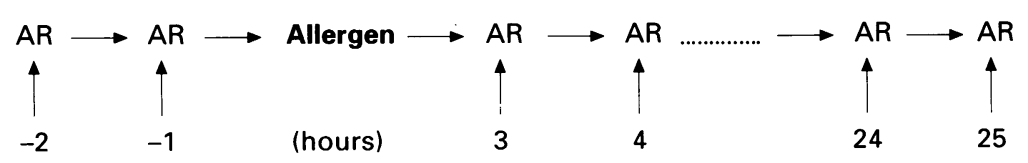

Figure 1 Study protocol; $A R=$ airway responsiveness.

\section{STUDY DESIGN}

The study was conducted in two phases: phase 1 involved a crossover study measuring airway responsiveness to histamine and MBS before and after both allergen and methacholine control challenges and phase 2 involved measurements of airway responsiveness to histamine and MBS before and after allergen challenge alone (fig 1).

\section{Phase 1}

Six subjects attended for two study days, each of 11 hours maximum duration and separated by a period of 21 days. On each occasion they were challenged with either allergen or methacholine (which served as a physiological control). Measurements of airway responsiveness to MBS and histamine were made before and after these challenges. The time points for the measurements of airway responsiveness were at two and one hours before and three and four hours after the allergen/control challenge. The order of the study days (that is, allergen or methacholine) was randomised for all subjects. The sequence of $\mathrm{MBS}$ and histamine inhalation was the same for each subject on both study days. Each individual was therefore randomised to one of two groups determining the order of the stimuli. Three patients received histamine challenges before MBS - that is, two hours before and three hours after the challenge and the remaining three patients received MBS challenge first at each time point. Both before and after allergen challenge histamine and MBS challenges were only performed if the $\mathrm{FEV}_{1}$ had recovered to within $10 \%$ of the baseline value.

Control and allergen challenges were administered in a single blind manner. Histamine and MBS challenges were performed by an independent operator (LJC) who remained blinded to allergen or control challenges.

On both study days measurements of $\mathrm{FEV}_{1}$ were recorded for a maximum of eight hours after allergen/control challenges. Before leaving the unit all subjects received nebulised budesonide $2 \mathrm{mg}$ and, if required, nebulised salbutamol $2.5 \mathrm{mg}$. 
Phase 2

During phase 2 a further 12 subjects attended for one study day and were admitted overnight to the unit for at least 28 hours. Measurements of airway responsiveness to MBS and histamine were made at two and one hours before and at three and four hours after allergen challenge in a similar manner to phase 1 and, additionally, at 24 and 25 hours after allergen challenge. As in phase 1, each individual was randomly allocated to one of two groups defining the sequence in which histamine and MBS challenges were done. Allergen challenges were administered by the attending physician in an open manner who also administered the preallergen histamine and MBS challenges. The challenges at three and four hours and 24 and 25 hours after allergen were performed by an independent observer (LJC) who remained blinded to the pre-allergen $\mathrm{PC}_{20}$ data. As in phase 1 , at all time points histamine and MBS challenges were only performed if the $\mathrm{FEV}_{1}$ had recovered to within $10 \%$ of the baseline value.

Measurements of $\mathrm{FEV}_{1}$ were made half hourly for 4-10 hours and hourly thereafter prior to undergoing further airway responsiveness measurements at 24 and 25 hours after allergen challenge. After the final challenge, before leaving the unit, all subjects received nebulised budesonide $2 \mathrm{mg}$ and nebulised salbutamol $2.5 \mathrm{mg}$.

\section{MATERIALS}

On each study day fresh solutions of methacholine, histamine, MBS, (Sigma Chemicals, Poole, UK) and allergen (Aquagen SQ, ALK, Horsholm, Denmark) were made in $0.9 \%$ saline. The concentration ranges for methacholine and histamine were $0.03-32 \mathrm{mg} / \mathrm{ml}$ and for MBS $0.063-160 \mathrm{mg} / \mathrm{ml}$. Freeze dried allergen extracts were used to make dilutions from a stock solution of $100000 \mathrm{IU} / \mathrm{ml}$ to give final concentrations of $200,1000,2500,5000$, 12500,25000 , and $50000 \mathrm{IU} / \mathrm{ml}$. The allergen used for each subject was predicted by the response to skin prick testing.

\section{MEASUREMENT OF PULMONARY FUNCTION AND $\mathrm{PC}_{20}$}

Pulmonary function was measured with a dry wedge spirometer (Vitalograph, Buckingham, UK). A standard challenge protocol was used for both MBS and histamine provocation tests. On arrival in the laboratory each subject rested for 15 minutes before three measurements of $\mathrm{FEV}_{1}$ were taken at one minute intervals, the best of which was taken as the baseline. Subjects then inhaled five breaths of saline control by inspiring slowly from functional residual capacity (FRC) to total lung capacity (TLC) followed by breath holding for five seconds. $\mathrm{FEV}_{1}$ was measured two minutes after inhalation of the saline. Unless a fall in $\mathrm{FEV}_{1}$ of $>10 \%$ was observed after saline, subjects inhaled five breaths of serially doubling increments of either histamine or MBS at three minute intervals until a $20 \%$ fall in $\mathrm{FEV}_{1}$ was recorded from the post-saline value. A log dose response curve was constructed for each agonist and the provocative concentration causing a $20 \%$ fall in $\mathrm{FEV}_{1}\left(\log _{10} \mathrm{PC}_{20}\right)$ was calculated by linear interpolation.

\section{ALLERGEN CHALLENGE}

Allergen challenge was commenced one hour after the second pre-allergen $\mathrm{PC}_{20}$ bronchial challenge and was administered as five nebulisations from a dosimeter (MB3) similar to the other airway challenges. The initial dose for the allergen inhalation test was $200 \mathrm{IU} / \mathrm{ml}$ and $\mathrm{FEV}_{1}$ was measured five and 10 minutes after administration of the allergen. Serially increasing doses of allergen were inhaled and the cumulative dosage resulting in a fall of at least $15 \%$ in $\mathrm{FEV}_{1}$ after saline diluent within 10 minutes was recorded and constituted an adequate challenge and the early asthmatic response (EAR). The FEV 1 was recorded every 15 minutes for the first hour and half hourly thereafter. The LAR was defined as a fall in $\mathrm{FEV}_{1}$ of $15 \%$ from the post-saline $\mathrm{FEV}_{1}$ between five and eight hours on at least two occasions (phase 1) and between five and 10 hours on at least three occasions (phase 2).

CONTROL CHALLENGE (PHASE 1 ONLY)

In a similar manner to the allergen challenge, measurements of $\mathrm{FEV}_{1}$ were recorded five and 10 minutes after inhalation of serial increments of methacholine. The challenge was terminated when a fall in $\mathrm{FEV}_{1}$ of $\geq 25 \%$ from the postsaline value was observed. To maintain subject blindness, methacholine was administered in fourfold increments to provide challenge conditions similar to the allergen day in terms of both the number of doses delivered and the degree of bronchoconstriction experienced.

\section{ANALYSIS OF DATA}

All airway data are expressed as means (SE) except the $\mathrm{PC}_{20}$ data which were expressed as geometric means. The extent of the LAR was assessed as the maximal fall in $F E V_{1}$ from baseline and expressed as percentage change. All $\mathrm{PC}_{20}$ values were log transformed for analysis.

The effect of allergen on airway responsiveness to both histamine and MBS was expressed in terms of doubling dose changes and calculated using the formula:

$\left[\log _{10} \mathrm{PC}_{20}\right.$ (pre-allergen) - $\log _{10} \mathrm{PC}_{20}$ (postallergen)] $/ \log _{10} 2$

where the post-allergen $\mathrm{PC}_{20}$ was either three or 24 hours after challenge.

All data were analysed using the Student's $t$ test for matched pairs, a $p$ value of $\leq 0.05$ being considered significant. 
Table 2 Individual airway responsiveness to bronchial challenges at three and 24 hours after allergen challenge

\begin{tabular}{|c|c|c|c|c|c|c|c|}
\hline \multirow[t]{2}{*}{ Patient no. } & \multicolumn{3}{|c|}{$\log P C_{20}$ histamine } & \multicolumn{3}{|c|}{$\log P C_{20}$ metabisulphite } & \multirow{2}{*}{$\begin{array}{l}\text { Maximum \% fall } \\
F E V,(L A R)\end{array}$} \\
\hline & Pre & 3 hours post & 24 hours post & Pre & 3 hours post & 24 hours post & \\
\hline 1 & 0.73 & 0.44 & - & 1.22 & 1.15 & - & - \\
\hline 2 & -0.72 & -1.18 & - & 0.53 & 0.52 & - & - \\
\hline 3 & 0.57 & 0.43 & - & 0.82 & 1.06 & - & - \\
\hline 4 & -0.02 & -0.21 & - & 1.18 & 1.10 & - & - \\
\hline 5 & 0.10 & 0.15 & - & 0.81 & 0.67 & - & - \\
\hline 6 & 0.18 & 0.15 & - & 0.75 & 0.81 & - & - \\
\hline 7 & 0.43 & -0.01 & -0.79 & 0.73 & 0.95 & 0.96 & 30 \\
\hline 8 & -0.19 & -0.42 & -0.73 & 0.76 & 0.78 & 0.79 & 31 \\
\hline 9 & -0.01 & -0.27 & -0.51 & 1.20 & 0.33 & 0.91 & 19 \\
\hline 10 & 0.88 & 0.78 & 0.62 & 0.89 & 1.12 & 1.25 & 17 \\
\hline 11 & -0.20 & -0.26 & -0.30 & 0.77 & 0.96 & 1.09 & 19 \\
\hline 12 & -1.04 & - & -1.12 & 0.58 & - & 0.50 & 37 \\
\hline 13 & -1.17 & -1.52 & - & 0.1 & - & - & 29 \\
\hline 14 & 0.71 & -0.45 & -0.56 & 0.50 & 0.37 & 0.81 & 20 \\
\hline 15 & - & - & - & 0.84 & 0.59 & - & 13 \\
\hline 16 & -0.01 & -0.03 & -0.19 & 0.71 & 0.85 & 0.96 & 7 \\
\hline 17 & 0.32 & -0.24 & -0.42 & 1.05 & 0.27 & 0.67 & 10 \\
\hline 18 & 0.28 & 0.28 & 0.55 & 0.90 & 0.75 & 1.14 & 6 \\
\hline Mean (SE) & $0.05(0.14)$ & $-0.15(0.15)$ & $-0.34(0.18)$ & $0.80(0.06)$ & $0.77(0.07)$ & $0.91(0.07)$ & \\
\hline $\begin{array}{l}\text { Geometric mean } \\
(\mathrm{mg} / \mathrm{ml})\end{array}$ & 1.11 & 0.70 & 0.45 & 6.25 & 5.84 & 8.09 & \\
\hline
\end{tabular}

\section{Results}

RESPONSE TO ALLERGEN CHALLENGE/BASELINE LUNG FUNCTION

The mean percentage predicted $\mathrm{FEV}_{1}$ for all subjects was $97(1.6) \%$. There was no difference in baseline lung function on the study days nor was there any significant difference in baseline lung function between those showing either single or dual response to allergen (LAR, mean $\mathrm{FEV}_{1} 97.5$ (2.0)\% predicted; non-LAR mean $\mathrm{FEV}_{1} 95.5$ (2.5)\% predicted; table 1).

In both phases all 18 subjects tolerated the acute allergen response well and demonstrated an EAR (mean maximum fall in $\mathrm{FEV}_{1}$ of 32.8 (3.9)\%). The mean maximum percentage fall in $\mathrm{FEV}_{1}$ for EAR was similar for single and dual responders (table 1).

In phase 1 all six subjects experienced equivalent acute bronchoconstriction following allergen and control challenge; after allergen the mean maximum fall in $\mathrm{FEV}_{1}$ was 33.5 (3.6) $\%$; after methacholine the mean maximum fall in $\mathrm{FEV}_{1}$ was 36.1 (4.5)\%. All subjects showed an LAR after allergen challenge. In phase 1 the maximum fall in the $\mathrm{FEV}_{1}$ during the LAR is not defined as each subject received a bronchodilator once they fulfilled the criteria for the late response. On the control day no subject experienced bronchoconstriction between five and eight hours.

In phase 2 eight of the 12 subjects experienced an LAR with a mean maximum fall in $\mathrm{FEV}_{1}$ of 25.3 (2.6)\%. The four subjects who did not show an LAR had a mean maximum fall in $\mathrm{FEV}_{1}$ of 9.0 (1.6)\% 4-10 hours after allergen challenge (table 1 ).

AIRWAY RESPONSIVENESS AFTER ALLERGEN

In phase 1 all six subjects completed the protocol. In phase 2 nine of the 12 subjects completed the protocol in full.

From phase 2 incomplete data are presented on two subjects showing LAR. Subject 12 had a prolonged EAR and was not within $10 \%$ of baseline $\mathrm{FEV}_{1}$ at 3-4 hours. Subject 13 had not recovered to within $10 \%$ of baseline $\mathrm{FEV}_{1}$ for a three hour post-allergen MBS challenge and had a profound LAR precluding any chal- lenge at 24 and 25 hours. One of the four subjects without an LAR (no. 15) failed to recover to within $10 \%$ of baseline $\mathrm{FEV}_{1}$ following MBS challenge and therefore did not undergo histamine challenges at any time point. In addition, he developed a profound LAR and was not challenged at 24-25 hours.

In the two phases combined evaluable data were available on 16 subjects (nos $1-11,13$, 14, and 16-18) for a comparison of airway responsiveness to histamine before and three hours after allergen, and also on 16 subjects (nos 1-11 and 14-18) to compare airway responsiveness to MBS. In phase 2 data were available on 10 subjects to compare airway responsiveness to histamine (nos 7-12, 14, 1618) and MBS (nos 7-12, 14, 16-18) before and 24 hours after allergen (table 2).

For the group as a whole there was a significant increase in airway responsiveness to histamine challenge at both three and 24 hours following allergen challenge compared with the pre-allergen value (change in mean doubling dose $0.89(0.25)$ at three hours $(n=16)$ and $1.53(0.52)$ at 24 hours $(\mathrm{n}=10) ; \mathrm{p}<0.05$ at both time points; table 2, fig 2). For subjects with an LAR the change in mean doubling dose was $0.95(0.28)$ at three hours $(\mathrm{n}=13)$ and $1.88(0.62)$ at 24 hours $(n=7) ; p<0.05$ at both time points (table 2). The absence of an LAR did not significantly affect the result as

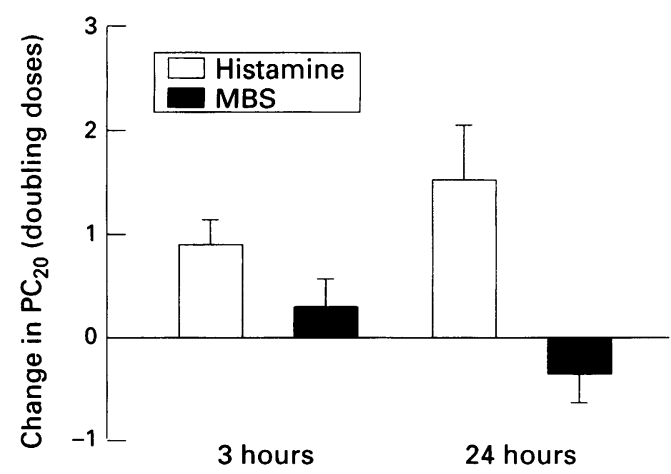

Figure 2 Doubling dose shift from baseline in airway responsiveness to histamine and sodium metabisulphite at three and 24 hours after allergen challenge. 


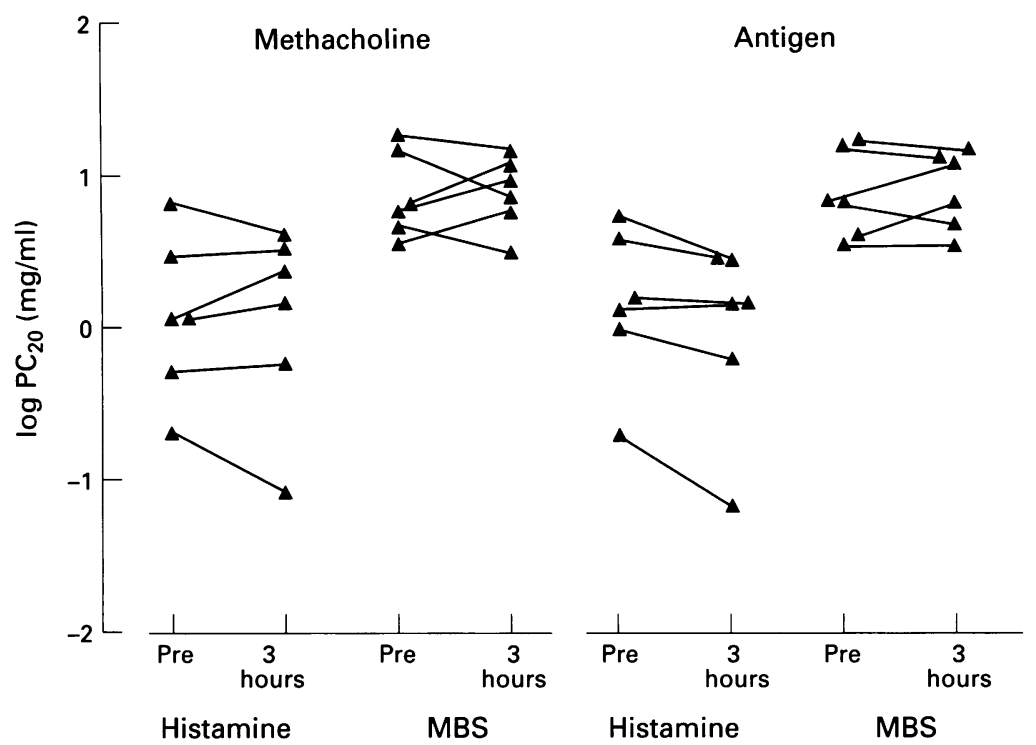

Figure 3 Individual data showing $\log P C_{20}$ for six subjects undergoing histamine and sodium metabisulphite challenges before and three hours after allergen challenge and control challenge (methacholine). effect rather than simply a consequence of airway calibre alone.

Our observed increase in airway responsiveness to histamine is compatible with other data on direct bronchoconstrictor challenges after allergen. ${ }^{3-7}$ The mechanisms underlying this are unclear but may be due to a number of inflammatory changes in the airway. ${ }^{34}$ The change in airway responsiveness may reflect increased activity or sensitivity of cells, nerves, or smooth muscle as a consequence of this inflammation. ${ }^{13}$ Airway smooth muscle is under the influence of inflammatory mediators released during the LAR which may be responsible for increased smooth muscle responsiveness. ${ }^{313}$ Only a part of the observed reduction in $\mathrm{PC}_{20}$ can be attributed to changes in airway calibre alone. ${ }^{14}$ Also, it is possible that damage to the airway epithelium during the inflammatory response to allergen will facilitate passage of the bronchoconstricting stimulus to its target site. ${ }^{15}$ All of these factors would predict an increase in airway responsiveness irrespective of the underlying stimulus. Thus, our failure to demonstrate an effect of allergen on MBS challenge is surprising. We expected that allergen would provoke an increase in airway responsiveness to MBS at least comparable to that of histamine.

The aim of our study was to assess the contribution of neural pathways to increased airway responsiveness following allergen using MBS as an indirect neural stimulus. Previous studies have shown increased airway responsiveness to indirect challenge with AMP similar to that of methacholine three hours after allergen, ${ }^{6}$ but a greater and more prolonged increase to bradykinin than to methacholine. ${ }^{7-9}$ This effect on airway responsiveness to bradykinin persists for up to three weeks and has been attributed to upregulation of neural reflexes. ${ }^{78}$ Thus, the results of our study are even harder to explain as the constrictor effects of MBS and bradykinin have a similar pharmacological profile. Airway responsiveness to both bradykinin and MBS is attenuated by anticholinergic agents, ${ }^{1617}$ cromoglycate, ${ }^{1819}$ and by bradykinin $\beta_{2}$ receptor antagonists. ${ }^{20}$ This evidence suggests that similar neural mechanisms underlie the constrictor action of these two agents. If upregulation of neural reflexes was implicated in the increase in airway responsiveness to bradykinin after allergen, it might be expected that airway responsiveness to MBS would also increase after allergen. Our results suggest that the shared mechanisms of bronchoconstriction of these agents do not contribute to the pathophysiology of increased airway responsiveness following allergen challenge.

It is possible that differences in the bronchoconstrictor action of MBS and bradykinin may explain our results and also account for some of the processes involved in changes in airway responsiveness after allergen challenge. Inhibition of the cyclo-oxygenase pathway with flurbiprofen significantly attenuated airway responsiveness to MBS. ${ }^{21}$ By contrast, airway responsiveness to bradykinin was unaffected by either flurbiprofen ${ }^{22}$ or aspirin. ${ }^{16}$ Cyclo-oxygenase metabolites may therefore be involved 
in airway responsiveness to MBS but not to bradykinin. This distinction could be important if prostanoids modulate airway responses to allergen. Previous data are conflicting. A single dose of indomethacin attenuated the LAR but not the EAR to allergen, ${ }^{23}$ whereas twice daily dosing for two days reduced airway responsiveness to histamine at 24 hours without an effect on either the EAR or LAR. ${ }^{24}$ It is tempting to speculate that bronchoconstrictor prostanoids are released during the LAR resulting in a depletion of stores at 24 hours leading to partial refractoriness to MBS. This hypothesis can only be sustained if airway responsiveness to MBS is mediated at least in part by bronchoconstrictor prostanoids. ${ }^{21}$ As the EAR is unaffected and may even be increased by indomethacin, ${ }^{25}$ this does not explain our results on airway responsiveness to MBS at three hours. Indeed, the role of prostaglandins in MBS induced bronchoconstriction is far from clear as inhaled $\mathrm{PGE}_{2}$ protects against $\mathrm{MBS}$ challenge ${ }^{26}$ and indomethacin failed to inhibit the response to initial challenge but reduced refractoriness to subsequent challenge with $\mathrm{MBS}^{27}$ Thus, although cyclo-oxygenase products may contribute to allergen induced late responses, they are a complex family of inflammatory mediators with both bronchoconstrictor and bronchoprotective airway effects. We cannot therefore propose prostanoid involvement as an explanation for the lack of an effect on airway responsiveness to MBS following allergen challenge.

Indirect challenge with MBS and AMP may share similar neural pathways, at least in part, as airway responsiveness to both spasmogens is inhibited to the same degree by frusemide ${ }^{28}$ and nedocromil sodium or cromoglycate. ${ }^{1929}$ As with bradykinin, this putative shared mechanism cannot explain our results at three hours after allergen challenge. Allergen provoked an increase in airway responsiveness to AMP which is predominantly a mast cell stimulus at three but not at 24 hours. ${ }^{6}$ The absence of an effect on both challenges at 24 hours is either further indirect evidence that neural pathways are not upregulated by allergen or that the mechanism of MBS is in question.

Repeated MBS challenge at hourly intervals results in refractoriness and may explain our findings. ${ }^{27}$ In the present study MBS challenges were separated by five and 21 hours, respectively. Our previous observation that three serial MBS challenges at three hourly intervals did not exhibit refractoriness makes this unlikely. ${ }^{21}$ Cross refractoriness may exist between allergen and MBS. It is possible that allergen challenge may cause depletion of preformed neurotransmitters that participate in the action of MBS. The timing of challenges renders this unlikely. Furthermore, cross refractoriness may occur between histamine and MBS as each challenge was separated by an interval of one hour. Our study design allowed for this by balancing the sequence of challenges between subjects. Moreover, we established that cross refractoriness does not occur between histamine and MBS in a previous pilot study in our unit. Finally, we cannot account for the contrast in effect on airway responsiveness to histamine and MBS. We might reasonably have expected enhanced smooth muscle responsiveness irrespective of the stimulus as a consequence of allergic inflammation. ${ }^{31314}$ Indeed, anti-inflammatory treatment with 14 days treatment of budesonide reduced airway responsiveness to methacholine and MBS by an equivalent one doubling dose, implying an inflammatory influence on smooth muscle responsiveness independent of an indirect airway action of MBS. ${ }^{30}$

The results of our study may raise questions about the relative importance of neural factors in the aetiology of increased airway responsiveness following allergen challenge. Furthermore, we have demonstrated a clear distinction in airway responsiveness to two spasmogens with different airway actions, supporting the view that several mechanisms are involved in the pathogenesis of an allergen induced increase in airway responsiveness. Further studies comparing challenges with separate bronchoconstrictor actions may help to unravel these complex mechanisms.

1 Barnes PJ. New concepts in the pathogenesis of bronchial hyperresponsiveness and asthma. 7 Allergy Clin Immunol 1989;83:1013-26.

2 Hargreave FE, O'Byrne PM, Ramsdale EH. Mediators, airway responsiveness and asthma. $\mathcal{F}$ Allergy Clin Immunol 1985;65:76:272-6.

3 Durham SR. Late asthmatic responses. Respir Med 1990; 84:263-8.

4 Cockcroft DE, Ruffin RE, Dolovich S, Hargreave FE. Allergen-induced increase in non-allergic bronchial reactivity. Clin Allergy 1977;7:503-13.

5 Cockcroft DW, Murdock KY. Changes in bronchial responsiveness to histamine at intervals after allergen challenge. Thorax 1987;42:302-8.

6 Aalbers R, Kauffman HK, Koeter GH, Postma DS, De Vries K, De Monchy JGR. Dissimilarity in methacholine and adenosine 5 -monophoshate 3 and 24 hours after allergen challenge. Am Rev Respir Dis 1991;144:352-7.

7 Djukanovic R, Polosa R, Holgate ST. The effect of bronchial allergen challenge on methacholine and bradykinin airway responsiveness. Eur Respir f 1991;340s:584A

8 Djukanovic $R$. Is airways hyperreactivity selective or nonselective? Agents Actions 1993;43:231-9.

9 Berman AR, Togias AG, Skloot G, Proud D. Allergen challenge of atopic asthmatics enhances bronchial reactivity to bradykinin more than that to methacholine. Am $\mathcal{F}$ Respir Crit Care Med 1994;149:A1042.

10 Chung KF. Role played by inflammation in the hyperreactivity of the airways in asthma. Thorax 1986;42:657-62

11 Rogers DF, O'Connor BJ. Airway hyperresponsiveness: relation to asthma and inflammation. Thorax 1993;48: relation

12 Barnes PJ. Effect of nedocromil sodium on airway sensory nerves. f Allergy Clin Immunol 1993;92:182-6.

13 Cockcroft DW. Bronchial hyperresponsiveness. In: Mygind N, Pipkorn U, Dahl R, eds. Rhinitis and asthma. Copenhagen: Munkgaard, 1990:172-87.

14 Cartier A, Thompson NC, Frith PA, Roberts R, Hargreave $\mathrm{FE}$. Allergen-induced increase in bronchial responsiveness to histamine; relationship to the late asthmatic response and change in airway calibre. $\mathcal{F}$ Allergy Clin Immunol 1982; 70:170-7.

15 Boucher RC, Parte PD, Hogg JC. Relationship between airway hyperreactivity and hyperpermeability in Ascarissensitve monkeys. F Allergy Clin Immunol 1979;64:197-9.

16 Fuller RW, Dixon CM, Cuss FM, Barnes PJ. Bradykinininduced bronchoconstriction in humans. Mode of action. Am Rev Respir Dis 1987;135:176-80.

17 Bellingham GJ, Dixon CM, Ind PW. Inhibition of inhaled metabisulphite-induced bronchoconstriction by inhaled frusemide and ipratropium bromide. $\mathrm{Br} \mathcal{F}$ Clin Pharmacol 1992;34:71-4.

18 Dixon CM, Barnes PJ. Bradykinin-induced bronchoconstriction: inhibition by nedocromil sodium and sodium cromoglycate. Brf Clin Pharmacol 1989;27:831-6.

19 Dixon CM, Ind PW. Inhaled sodium metabisuphite induced bronchoconstriction: inhibition by nedocromil sodium and
sodium cromoglycate. Br f Clin Pharmacol 1990;30:371-6.

20 Mansour E, Ahmed A, Cortes A, Caplan J, Burch RM, Abraham WM. Mechanisms of metabisulfite-induced Abraham WM. Mechanisms of metabisulfite-induced
bronchoconstriction: evidence for bradykinin $\beta_{2}$-receptor stimulation. F Appl Physiol 1992;72:1831-7. 
21 O'Connor BJ, Barnes PJ, Chung KF. Inhibition of sodium metabisulphite induced bronchoconstriction by frusemide in asthma; role of cyclooxygenase products. Thorax 1994; 49:307-11.

22 Polosa R, Phillips GD, Lai CKW, Holgate ST. Contribution of histamine and prostanoids to bronchoconstriction provoked by inhaled bradykinin in atopic asthma. Allergy 1990;45:174-82.

23 Fairfax AJ, Hanson JM, Morley J. The late reaction following bronchial provocation with house dust mite allergen. Dependence on arachidonic acid metabolism. Clin Exp Allergy pendence on arach

24 Kirby JG, Hargreave FE, Cockcroft DW, O'Byrne PM. Effect of indomethacin on allergen-induced asthmatic responses. F Appl Physiol 1989; 66:578-83.

25 Fish JE, Ankin MG, Adkinson NF, Peterman VI. Indomethacin modification of immediate-type immunologic airway responses in allergic asthmatic and non-asthmatic subjects: evidence for altered arachidonic acid metabolism in asthma. Am Rev Respir Dis 1981;123:609-14.
26 Pavord ID, Wisniewski A, Mathur R, Wahedna I, Knox AJ, Tattersfield AE. Effect of prostaglandin E2 on bronchial reactivity to sodium metabisulphite and methacholine in patients with asthma. Thorax 1991;46:633-7.

27 Pavord ID, Wisniewski A, Tattersfield AE. Refractoriness to inhaled sodium metabisulphite in subjects with mild asthma. Eur Respir f 1994;7:50-4.

28 O'Connor BJ, Chung KF, Chen-Worsdell YM, Fuller RW, Barnes PJ. Effect of inhaled furosemide and bumetanide on adenosine $5^{\prime}$-monophosphate- and sodium metaon adenosine 5 -monophosphate- and sodium meta-
bisulfite-induced bronchoconstriction in asthmatic subbisulfite-induced bronchoconstriction in asth
jects. Am Rev Respir Dis 1991;143:1329-33.

29 Phillips GD, Scott VL, Richards R, Holgate ST. Effect of nedocromil sodium and sodium cromoglycate against bronchoconstriction induced by inhaled adenosine $5^{\prime}$ monophosphate. Eur Respir f 1989;2:210-7.

30 O'Connor BJ, Ridge SM, Barnes PJ, Fuller RW. Greater effect of inhaled budesonide on adenosine 5'-monophosphate-induced bronchoconstriction in asthma. $A m$ Rev Respir Dis 1992;146:560-4. 